ISSN: 0213-2052 - eISSN: 2530-4100

DOI: http://dx.doi.org/10.14201/shha2019373161

\title{
LA GUERRA DE TACFARINAS (17-24 D. C.): BALANCE HISTORIOGRÁFICO Y NUEVAS PERSPECTIVAS SOBRE LAS CAUSAS DE SU ESTALLIDO $^{1}$
}

\section{The War of Tacfarinas (17-24 AC): Historiographic Balance and new Perspectives about the Causes of its Outbreak}

\author{
Noelia CASES MORA \\ Universidad de Alicante \\ noelia.cases@ua.es
}

Fecha de recepción: 29-10-2018; aceptación definitiva: 2-3-2019

ORCID: 0000-0001-7991-083X

RESUMEN: Este artículo plantea una revisión historiográfica de la guerra de Tacfarinas en el norte de África durante el gobierno del emperador Tiberio (17-24 d. C.), con el objetivo de comprender sus causas y consecuencias para la política romana. A pesar de la gran cantidad de trabajos realizados en torno al testimonio de Tácito en los Annales, la aplicación de bases teóricas novedosas y la revisión de otros materiales nos permiten

1. Se han utilizado los términos de revuelta, rebelión y guerra para definir este conflicto. Tácito (Ann. II, 52) lo califica como latrocinium, vinculándolo con el carácter de bandido de la cabeza visible de las tribus africanas implicadas y negando el rango de bellum. Hemos utilizado el concepto de guerra porque se ajusta más a la larga duración del conflicto, frente al concepto de revuelta, que denota un suceso más puntual. 
proponer nuevas ideas al respecto. Asimismo, reflexionamos sobre el hecho de que Tácito sea el único autor que presta atención al conflicto.

Palabras clave: Tacfarinas; Tiberio; musulamios; norte de África; historiografía.

ABSTRACT: This paper reviews the war of Tacfarinas in the North of Africa during the government of the emperor Tiberius (17-24 AC), in order to understand his causes and consequences for Roman policy. Although a lot of papers have been done about the testimony of Tacitus in Annales, new theories and methods can allow us to argue about new ideas. In addition, we consider the fact that Tacitus is the only author that pays attention to the conflict between Rome and Tacfarinas.

Keywords: Tacfarinas; Tiberius; musulamii: North Africa; historiography.

\section{INTRODUCCIÓN}

En el 17 d. C. estalló un conflicto en el África Proconsular entre la confederación númida de los musulamios (junto con mauros, cinitios y garamantes), encabezados por Tacfarinas ${ }^{2}$, quien había prestado servicios en el ejército romano ${ }^{3}$, y el Imperio romano. Después de que varios procónsules de la provincia lucharan contra los sublevados, finalmente fue P. Cornelius Dolabella quien derrotó a Tacfarinas en la batalla de Auzea/ Auzia (24 d. C.) tras varios años de guerrilla ${ }^{4}$. Puesto que la narración de Tácito en sus Annales es prácticamente la única fuente para el análisis del conflicto y no especifica cuáles fueron las causas que lo desencadenaron', el objetivo que nos proponemos es analizar las propuestas historiográficas al respecto, así como las consecuencias que tuvo el conflicto en la organización provincial del África romana y en su concepción dentro de la política imperial de Tiberio.

2. Podríamos plantearnos hasta qué punto Tacfarinas es el líder del conjunto de tribus africanas, si es reconocido como tal o solo un interlocutor con Roma que, por ello, ha sido reflejado como líder en las fuentes romanas. Lo cierto es que pocos autores se han cuestionado el liderazgo de Tacfarinas.

3. TAC., Ann. II, 52. Seguimos la traducción de los Annales de Tácito realizada por J. L. Moralejo (1979).

4. TAC., Ann. IV, 25.

5. Tácito (Ann. II, 52) no señala las causas ni el pretexto del conflicto, sino que empieza directamente con el relato del suceso, siendo escasas las referencias que nos permiten pensar en posibles razones. 
PERSPECTIVAS SOBRE LAS CAUSAS DE SU ESTALLIDO

Por otra parte, se han realizado interesantes estudios en relación a la visión de Tacfarinas como latro, partiendo de la descripción de Tácito, así como sobre la etnicidad de las comunidades africanas y la identidad variable de determinados personajes que se mueven dentro y fuera de las estructuras de Roma, como es el caso del protagonista de esta guerra. Por ello, será interesante realizar también una valoración en torno a estos aspectos, con el objetivo de insertar la revuelta de Tacfarinas dentro de los discursos de identidad y alteridad que se han desarrollado en las últimas décadas ${ }^{6}$.

Para comprender este conflicto es necesario tener en cuenta el papel fundamental de la geografía y los recursos del territorio. Por ello, la hipótesis que planteamos es la importancia fundamental de los modelos de explotación económica del territorio y sus recursos como parte esencial de las causas que dieron lugar al estallido de la guerra de Tacfarinas. De igual modo, consideramos que sería interesante tener en cuenta el papel determinante que pudo tener la capacidad de moverse en un territorio con una geografía compleja, por lo que una acción del Imperio romano que afectara a esta capacidad de movimiento de la población local también pudo conducir a la revuelta.

La metodología, dado que la principal fuente de estudio de la que disponemos es el testimonio de Tácito, consistirá en el análisis del mismo y la revisión bibliográfica sobre las interpretaciones realizadas al respecto. También prestaremos atención a los testimonios numismáticos, epigráficos y arqueológicos que, en las investigaciones desarrolladas durante las últimas décadas, han aportado nuevos datos para la interpretación de la guerra de Tacfarinas, especialmente sobre las causas y el contexto histórico previo, gracias al estudio de nuevas fuentes. El conflicto tuvo lugar entre los años 17 y 24 d. C., durante el gobierno de Tiberio, en un espacio geográfico complejo donde se movieron las tribus africanas implicadas y las legiones romanas.

La geografía del África Proconsular, provincia creada por Augusto en el 27 a. C. que podemos identificar en parte con el actual país de Túnez, se caracteriza por una serie de cadenas montañosas, entre ellas la cordillera

6. Podemos destacar los siguientes estudios: Devillers, O.: "Le Rôle des passages relatifs à Tacfarinas dans les Annales de Tacite", en Mastino, A. (ed.): L'Africa Romana. Atti del VIII convegno di studio, Sassari, 14-16 diciembre 1990, 1. Sassari, 1991, pp. 203211; Fentress, E. W. B.: "Romanizing the Berbers", Past and Present, 190, 2006, pp. 3-34; GONZALÈs, A.: "La révolte comme acte de brigandaje: Tacite et la révolte de Tacfarinas", en Khanoussi, M.; Ruggeri, P. y Vismara, C. (eds.): L'Africa romana. Atti del XII convegno di studio, Olbia, 12-15 diciembre 1996, 2. Sassari, 1998, pp. 937-958; GrüNEWAld, T.: Bandits in the Roman Empire: myth and reality. London, 2004. 
del Atlas, que ocupan la mitad septentrional de la provincia y atraviesan el territorio transversalmente desde el suroeste hacia el noreste. En este espacio coinciden valles fértiles y territorios montañosos como el Aurés o la Dorsal tunecina, donde el territorio es muy apropiado para el cultivo. Además, se encuentra al río más importante de la zona, el Medjerda, que desemboca en el golfo de Túnez. Más al sur de la antigua provincia romana encontramos un paisaje meseteño que desciende hasta la zona formada por lagos salados que se extienden de este a oeste, destacando Chott el-Djerid, en un ámbito semidesértico. En la zona más austral se da paso al desierto del Sahara, que ocupa gran parte del sur de la actual Túnez.

En este amplio territorio, encontramos diversas tribus o gentes que se enfrentarán a Roma en este conflicto. En primer lugar, los musulamios, quienes eran uno de los pueblos más importantes de Numidia según Tácito ${ }^{7}$, pero cuya ubicación ha planteado problemas. Se ha discutido si eran una facción de los gétulos o una confederación númida, aunque parece que la discusión historiográfica se ha inclinado por la segunda opción ${ }^{8}$. Ocupaban el territorio comprendido entre los confines de Mauretania y las costas de la Pequeña Sirte. Concretamente, Y. Le Bohec ${ }^{9}$ los sitúa en dos zonas: una parte en el sureste de Constantina y otra entre Madauros, Tébessa y l'Hr Kemellel, es decir, una vasta zona en la actual frontera tunecino-argelina, como también señaló previamente Desanges ${ }^{10}$.

En cuanto a los cinitios, habitaban los alrededores de la Pequeña Sirte, en la región de Gibthis (Bou Ghara) ${ }^{11}$, lo que ha sido corroborado por una inscripción hallada en Thysdrus (El Djem) que cita un praef(ectus) gentis

7. TAC., Ann. II, 52.

8. Los defensores de la primera hipótesis (Coltelloni-Trannoy, M.: Le royaume de Maurétanie sous Juba II et Ptolémée (25 av.J. C. - 40 ap.J. C.). Paris, 2002, p. 74) esgrimen razones como el testimonio de Apuleyo, originario de Madaura, pero se autodenominaba semi-númida y semi-gétulo (Apul., Apol. XXIV 1). Los seguidores de la segunda propuesta (CAMPs, G.: Aux origines de la Berberie. Massinissa ou les débuts de l'histoire, Libyca, VIII, 1960, pp. 155-156; LASSÈre, J. M.: "Un conflit "routier": observations sur les causes de la guerre de Tacfarinas", Antiquités africaines, 18, 1982, p. 23; LE BOHEC, Y.: La Troisième Légion Auguste. Paris, 1989, p. 343) rebaten la información de Apuleyo, especialmente Camps, que constata que las fuentes literarias que tratan sobre los musulamios no los califican de gétulos, sino como númidas. p. 57.

9. Le Bohec, Y.: Histoire de l'Afrique Romaine (146 J.-C.-439 après J.-C.). Paris, 2005,

10. Desanges, J.: “Les territoires Gétules de Juba II", Revue des Études Anciennes, 66, 1964, pp. 33-47.

11. Desanges, J.: Catalogue des tribus africaines de l'antiquité classique a l'ouest $d u$ Nil. Université de Dakar, Publications de la section d'Histoire, 1962, p. 86. 
PERSPECTIVAS SOBRE LAS CAUSAS DE SU ESTALLIDO

Cinithiorum $^{12}$. Los mauros, dirigidos por Mazippa, se situaban en la zona de la Mauretania próxima al Aurés. Por último, los garamantes ocupaban una región que, en opinión de Romanelli ${ }^{13}$, era de difícil delimitación por la discrepancia de las fuentes ${ }^{14}$, pero actualmente se piensa que se dividían en dos grupos, uno situado en la región de Fezán y otro en la región de las Sirtes ${ }^{15}$.

El amplio territorio donde se movían estas tribus se caracterizaba por una economía de carácter seminómada mediante la que organizaban su actividad con desplazamientos estacionales entre la zona montañosa y el valle, combinando la agricultura y la ganadería. Además, un factor importante fue la temprana influencia sobre estas poblaciones de las ciudades de la costa y, por medio de estas, las de Cartago y Roma. Sin embargo, no se sedentarizaron más que a partir de la política que los Flavios emprendieron contra los garamantes y las tribus de la Sirte ${ }^{16}$, manteniendo los movimientos estacionales hasta entonces.

Tal y como indica Tácito, la amplitud del conflicto fue considerable, pero no abarcó todo el norte de África, como señalaron en su momento algunos autores ${ }^{17}$. Por su parte, J. Desanges ${ }^{18}$ considera que la lucha se extendió por la Pequeña Sirte y quizás más allá, cuestionando la autoridad de Juba II y después de su sucesor Ptolomeo. Sin embargo, lo cierto es que delimitar con precisión el escenario de la guerra resulta difícil, pero a juzgar por los pueblos que intervinieron en la misma (musulamios, cinitios, mauros y garamantes) podemos considerar que esta se desarrollaría al sur y al oeste de la provincia de África ${ }^{19}$. Además, consideramos que la vinculación con la cordillera del Aurés es clave, donde además se situaba la legio III Augusta. Se trataba de un espacio clave, puesto que conectaba el

12. CIL VIII, 10500: L(ucio) Egnatuleio P(ubli) f(ilio) Gal(eria) Sabino pontific(i) / palatuali proc(uratori) Aug(usti) XXXX Galliarum / proc(uratori) Aug(usti) ad epistrategian Thebaidos / proc(uratori) Aug(usti) ad census accipiendos / Macedoniae praef(ecto) gentis Cinithiorum / trib(uno) leg(ionis) IIII Scythicae lleg(ionis) - - - / / Geminae flam(ini) Aug(usti) clol(oniae) Thysdritanae] / Egantuleia P(ubli) f(ilia) Sabina F[- - - / L(ucius) Egnatuleius Sabinus T[---]/cnidius / procl- - - ius

13. Romanelli, P.: Storia delle province romane dell'Africa. Roma, 1959, p. 178.

14. Heródoto (IV, 183) los sitúa desde el oasis de Aoudjila hasta Zella, al sureste del oasis de Djofra; Estrabón (XVII, 3, 23) desde el sur de Mauretania hasta el sur de la Cirenaica; y Plinio (NH, V, 35-38) al sur de los Macae y Asbytae.

15. Berthier, A.: La Numidie: Rome et le Maghreb. Paris, 1981, p. 97.

16. Falomir, C.: Juba II: rey de los Mauros y los Libios. Tesis Doctoral, Universidad de Valencia, 2013, p. 241.

17. Romanelli, P.: op. cit., p. 228.

18. Desanges, J.: op. cit., p. 118.

19. Le Bohec, Y.: La Troisième Légion Auguste. Paris, 1989, pp. 343-344. 
valle y la cordillera y, en consecuencia, esencial para la trashumancia. Por lo tanto, parece evidente que el control de esta zona de paso de las tribus africanas sería vital para Roma para poder tener el control de la región.

\section{Fuentes literarias de la guerra de Tacfarinas: los Annales de Tácito}

La narración de Tácito en los Annales sobre la guerra de Tacfarinas constituye la principal fuente de información para conocer este conflicto ${ }^{20}$. La abundancia de detalles que proporciona se explica por la consulta de las acta Senatus, una especie de recopilación de noticias breves sobre historia interior ${ }^{21}$. Es remarcable que ni Plinio ni Dión Casio hacen referencia a ella, así como tampoco Suetonio. Solo encontramos otras referencias en Veleyo Patérculo ${ }^{22}$, que hace una simple alusión al proconsulado y al triunfo de Iunius Blaesus, y en Aurelio Víctor ${ }^{23}$, que se refiere a la relación de gétulos y Tacfarinas. En consecuencia, dado que la única información en las fuentes literarias reside en los Annales de Tácito, es necesario plantear qué importancia tuvo en Roma este conflicto. Si solo Tácito rinde cuenta de ello, y lo hace dentro de unos objetivos propios como veremos, quizá cabe cuestionar el alcance del conflicto en el contexto general del Imperio.

De igual forma, y debido al nivel de detalle que posee la narración de este historiador romano, cabe plantearse por qué Tácito decide tratar de forma detallada el conflicto con Tacfarinas y, en este sentido, qué significado tienen estos pasajes al integrarse en el resto de la obra de los Annales. Con respecto al sentido de la atención prestada por Tácito al conflicto con Tacfarinas, R. Syme ${ }^{24}$ considera que el hecho de la guerra se produzca en África permite aludir a la obra de Salustio dedicada a Jugurta y, a la vez, evocar la República. Otras interpretaciones aluden al relato de Tácito como un asunto del Senado romano, no como un aspecto de política exterior, puesto que se desarrolla en la provincia senatorial de África. De este modo, se ha señalado que el lugar donde aparece la primera mención sobre Tacfarinas, al final de un año, es insólito para un pasaje sobre un

20. TAC., Ann. II, 52; III, 20-21, 32, 73-74; IV, 23-26.

21. Syme, R.: "Tacfarinas, the Musulamii and Thubursicu", en Coleman-Norton, P. R.; BOURNe, F. C. y Fine, J. V. A. (eds.): Studies in Roman economic and social history in honor of Allan Chester Johnson. Princeton, 1951, p. 115.

22. VELL., II, 125.

23. Aur. VIC., De Caes. II, 3.

24. Syme, R.: op. cit., p. 120. 
PERSPECTIVAS SOBRE LAS CAUSAS DE SU ESTALLIDO

asunto extranjero, pero no si lo consideramos como asunto del Senado ${ }^{25}$. Por otro lado, también constatamos cierta dispersión de las noticias sobre Tacfarinas, que son repartidas en cuatro pasajes dentro de los Annales, mientras que, en el caso de los asuntos exteriores, Tácito reagrupa los hechos que han sucedido durante varios años. Además, las menciones a Tacfarinas tienen lugar en los contextos donde se narran hechos discutidos en el Senado.

Como consecuencia de ello, la guerra contra Tacfarinas sería ante todo, a los ojos de Tácito, un acontecimiento de orden senatorial, por lo que el papel de los pasajes relativos a esta dentro de los Annales se vincularía con el interés de mostrar la relación entre el emperador y el Senado ${ }^{26}$. Es necesario tener también en cuenta el contexto de Tácito al redactar los Annales, puesto que algunos autores han supuesto que existe un interés personal por África debido a la reorganización de esta por Trajano y el cursus honorum del historiador ${ }^{27}$, aunque consideramos que es difícil concluir que exista dicho interés a partir del relato de un único conflicto.

Por ello, la propuesta que creemos más acertada para interpretar los pasajes sobre Tacfarinas en los Annales es la de O. Devillers ${ }^{28}$, que concibe el relato de Tácito como una forma de mostrar el carácter de Tiberio y, según este, sus relaciones con el Senado. También A. Gonzalès ${ }^{29}$ considera que Tácito utiliza la narración de este conflicto como reflejo de las divergencias militares y políticas entre el emperador y el Senado, mientras que T. Grünewald ${ }^{30}$ incide en el pesimismo sobre el Principado que caracteriza el relato de Tácito. Así, el relato que hace Tácito de Tiberio es poco favorable, puesto que es global y algunos de sus defectos están presentes hasta el momento de su muerte. Pero también es evolutivo, en el sentido de que el principado de Tiberio se desarrolla según una gradación a peor.

Dentro de esta concepción de Tiberio en los pasajes sobre Tacfarinas hay un aspecto de la personalidad de Tiberio que destaca en dichos pasajes: los celos del emperador hacia todos aquellos que logran distinguirse $y$, en este caso concreto, contra los procónsules que tuvieron cierto éxito contra

25. Devillers, O.: "Le Rôle des passages relatifs à Tacfarinas dans les Annales de Tacite", en Mastino, A. (ed.): L'Africa Romana. Atti del VIII convegno di studio, Sassari, 14-16 diciembre 1990, 1. Sassari, 1991, pp. 204-206.

26. Devillers, O.: op. cit., p. 206.

27. SyMe, R.: op. cit., p. 120.

28. Devillers, O.: op. cit., p. 207.

29. Gonzalès, A.: op. cit., p. 938 54 .

30. GRÜNEWALD, T.: Bandits in the Roman Empire: myth and reality. London, 2004, p. 
Tacfarinas $^{31}$. Mediante su relato, Tácito intentaría culparle del fracaso de Roma para acabar con Tacfarinas, ofreciendo una imagen negativa de su carácter y de su gobierno mediante la exposición de la mala gestión de la guerra (junto con sus difíciles relaciones con el Senado), puesto que es incapaz de acabar con ella de forma eficaz, provocando que se extienda durante siete años, constituyendo el conflicto militar más destacado de los primeros años de su gobierno ${ }^{32}$. Tácito señala lo siguiente:

Por fin este año ( 24 d. C.) libró al pueblo romano de su larga guerra contra el númida Tacfarinas. Pues los generales anteriores, cuando creían que sus hechos eran suficientes para conseguir las insignias del triunfo, daban de lado al enemigo; y ya había tres estatuas laureadas en la Ciudad, mientras Tacfarinas seguía saqueando el África ${ }^{33}$.

Con el objetivo de mostrar esta idea, Tácito relata una serie de actos de Tiberio que fueron perjudiciales, como otorgar el triunfo a Furius Camilus rápidamente tras una victoria contra Tacfarinas sin que la guerra estuviera finalizada: "Con tal motivo fue mayor el entusiasmo de Tiberio al celebrar en el Senado su hecho de armas; Camilo las recibió impunemente gracias a la modestia de su vida, ${ }^{34}$; o declarar que esta estaba terminada en el 22 d. C. y permitir que Iunius Blaesus fuera aclamado como imperator cuando el conflicto seguía activo ${ }^{35}$. Sin embargo, el procónsul $P$. Dolabella, que acabó con la guerra de Tacfarinas, no recibió las insignias del triunfo porque Tiberio se lo negó en consideración a Sejano, para que la gloria de su tío Blaesus no se debilitase:

Tiberio no accedió a la petición de Dolabela cuando éste solicitó el triunfo, haciendo a Sejano la deferencia de que no se empañara la gloria de su tío Bleso. Mas no por ello fue Bleso más ilustre, y a Dolabela el honor negado le aumentó la gloria; en efecto, con un ejército menor se había traído cautivos notables, la muerte del jefe y la fama de haber puesto fin a la guerra ${ }^{36}$.

Este aspecto de la personalidad del emperador se manifiesta repetidamente en los Annales, especialmente cuando Tácito explica que una de las razones por las cuales Tiberio mantenía durante mucho tiempo a los

31. Aubrion, É.: Rhétorique et histoire chez Tacite. Metz, 1985, p. 274.

32. GRÜNEWALD, T.: op. cit., pp. 53-54.

33. TAC., Ann. IV, 23.

34. TAC., Ann. II, 52.

35. TAC., Ann. III, 74 .

36. TAC., Ann. IV, 26. 
PERSPECTIVAS SOBRE LAS CAUSAS DE SU ESTALLIDO

mismos hombres en algunos cargos era porque quedaba satisfecho con administradores mediocres ${ }^{37}$, como hace en el siguiente pasaje:

También era costumbre de Tiberio esa de mantener los mandos y conservar casi siempre a las mismas personas... Se suelen dar varias explicaciones: unos dicen que mantenía sus acuerdos como definitivos por huir de nuevas preocupaciones; otros piensan que lo hacía por envidia de que los disfrutaran muchos... en efecto, por una parte no buscaba virtudes eminentes, por otra aborrecía los vicios; de los mejores temía un peligro para sí, de los peores un deshonor para el estado ${ }^{38}$.

Esta desconfianza de los hombres brillantes o miedo a los eminentes virtutes puede ser interpretada, en realidad, como un componente del estereotipo de tirano ${ }^{39}$. Por tanto, para estudiar este conflicto a través de del relato de Tácito debemos tener en cuenta la importancia de este para el autor. Desde el punto de vista del suceso, no lo trata por su interés militar, sino por significación en el plano de la política interior, como un ejemplo de la relación entre el emperador y el Senado. Desde el literario, debemos considerar su intención de demostrar la evolución del gobierno de Tiberio, más que narrar una guerra destacada. En consecuencia, desde ambos puntos de vista, los pasajes dedicados a Tacfarinas son indisociables de la visión negativa que tiene Tácito del principado de Tiberio y los procedimientos que utiliza para convencer de la solidez de dicha visión ${ }^{40}$. Sin embargo, la visión negativa que expresa Tácito no solo afecta a Tiberio, sino que también Tacfarinas es retratado como un bandido o latro. Es interesante la definición que propone T. Grünewald ${ }^{41}$ al respecto, puesto que señala que Tacfarinas es caracterizado por Tácito como un "bandido común", frente a la concepción en las fuentes literarias de otros personajes que son definidos como latro pero con rasgos positivos, como por ejemplo Viriato. Tácito le define como desertor y bandido (desertor et praedo), apoyado por grupos que son partidarios del bandidaje, como podemos comprobar en el siguiente pasaje:

Cuentan que el César nunca se dolió más de una afrenta a él y al pueblo romano que en esta ocasión, en la que un desertor y bandolero actuaba a la manera de un enemigo. Ni siquiera Espartaco, que tras derrotar a tantos ejércitos consulares ponía fuego impunemente a Italia... ¡Cuánto menos se iba a comprar la paz y la concesión de tierras

37. GRÜNEWALD, T.: op. cit., p. 50.

38. TAC., Ann. I, 80, 2.

39. Devillers, O.: op. cit., p. 208.

40. Devillers, O.: op. cit., p. 211.

41. GRÜnewald, T.: op. cit., p. 50. 
a aquel bandolero de Tacfarinas en un momento del máximo esplendor romano! ${ }^{42}$.

El hecho de que se le defina como un bandido común se vincula con su condición de origen bárbaro, su estatus social bajo y, especialmente, su condición de desertor del ejército romano ${ }^{43}$. Además, la guerra que encabeza no es definida por Tácito con el término bellum sino latrocinium, debido a la táctica de guerrilla que utiliza Tacfarinas, siendo este un mero latro, a pesar de ser también un líder. La cuestión de la definición de la guerra es un aspecto muy importante, puesto que también supone un elemento de desprestigio hacia el emperador Tiberio que, al enfrentarse con un enemigo de tan bajo rango y no vencer de forma rápida, es objeto de una visión negativa. Otra cuestión es la identidad de Tacfarinas, que Tácito señala como líder del conjunto de tribus africanas que se alzaron contra Roma. En realidad, desconocemos qué papel desempeñó, si realmente ejerció un liderazgo, fue reconocido por el resto de tribus, o simplemente fue el interlocutor con respecto al Imperio y existió una organización menos piramidal, quizá con diferentes agrupaciones y líderes.

En conclusión, podemos señalar que los prejuicios de Tácito contra Tiberio actúan, en la narración de los Annales, en detrimento de la caracterización que hace de Tacfarinas. Por esta razón, este fue más menospreciado que los líderes de otras rebeliones y representado como un enemigo moralmente inferior, con el objetivo de justificar las críticas a Tiberio ${ }^{44}$. En este sentido, cabe destacar que Tácito no desprecia automáticamente los alzamientos provinciales como latrocinia, como podemos comprobar en la narración de la revuelta gala bajo Floro y Sacrovir, quienes no son definidos como latrones, quizá por su mayor grado de romanización ${ }^{45}$.

\section{CONTEXTO HISTÓRICO}

La resistencia armada después de la conquista inicial fue un fenómeno característico del proceso de pacificación en muchas de las provincias occidentales, teniendo en cuenta las particularidades del proceso de conquista y pacificación de cada lugar. Las razones de estas revueltas contra Roma que aparecen en las fuentes son variadas, aunque la razón que causaba el

42. TAC., Ann. III, 73.

43. GRÜNEWALD, T.: op. cit., p. 51.

44. GRÜNEWALD, T.: op. cit., p. 55.

45. TAC., Ann. III, 40. 
PERSPECTIVAS SOBRE LAS CAUSAS DE SU ESTALLIDO

mayor descontento era la imposición tributaria sobre la tierra ${ }^{46}$. En el caso africano, tras el comienzo de la ocupación con la Segunda Guerra Púnica, la presencia romana era mínima, centrándose en Cartago, y la provincialización no se produjo desde el primer momento, sino que se establecieron relaciones con el reino de Numidia y las élites gentilicias.

De este modo, los conflictos de Roma con la población local no comenzarían hasta finales del siglo i a. C. En el 19 a. C. tuvo lugar la revuelta de los garamantes y la siguiente revuelta se produciría en el $6 \mathrm{~d}$. C., cuando los gétulos protagonizaron un conflicto en las fronteras de la provincia de África Proconsular. Ya en el 17 d. C., y hasta el año 24, se produciría la guerra que es objeto de nuestro estudio con Tacfarinas, quien encabezó a los musulamios y otras gentes en un conflicto que cambiaría la percepción de Roma con respecto a África, de la necesidad de los recursos que aportaba y su capacidad para cortocircuitar la política imperial.

A partir de este momento, se abrió un periodo sin conflictos con el carácter de los anteriores, produciéndose pocos sucesos similares de relevancia con las poblaciones locales africanas. Sin embargo, la historiografía tradicional ha incidido en la incapacidad de dichas poblaciones para mantener la paz por su inclinación al conflicto. Quizá sí podríamos hablar de una tensión más o menos constante entre la población local y Roma, aunque de poca intensidad, que no daría lugar a grandes conflictos bélicos. Además, en muchos casos, las fuentes exageran la magnitud de los conflictos y su carácter con la intención de aumentar el prestigio de los generales romanos que salieron victoriosos de los mismos ${ }^{47}$.

Por otro lado, una idea esencial para entender el contexto del conflicto de Tacfarinas es la consideración, por parte del Imperio romano, de África como su "granero" abastecedor de trigo. Sobre todo con la larga duración de la guerra y sus resultados, Roma fue consciente de la importancia económica de este territorio. Dejando al margen las visiones estereotipadas de África como lugar donde solo se practicaba el pastoreo nómada o donde era imposible practicar una agricultura de grandes beneficios, lo cierto es que era un lugar con espacios muy productivos que interesaron a Roma. De hecho, algunos autores han planteado que la política imperial estaba dominada por la situación de la agricultura en Italia, devastada tras las guerras púnicas y las guerras civiles de los últimos años de la república,

46. Whittaker, C. R.: "Roman Africa: Augustus to Vespasian", en Bowman, A. K., Champlin, E. y Lintott, A. (eds.): The Cambridge Ancient History 10 (The Augustan Empire, 43 BC-AD 69). Cambridge, 1996, p. 593.

47. Le BoHec, Y.: op cit., p. 343. 
lo cual suponía que el trigo tuviera que traerse de las provincias, principalmente Egipto y África ${ }^{48}$.

Debemos comprender la guerra contra Tacfarinas dentro de este contexto, durante el gobierno de Tiberio (14-37 d. C.), así como es necesario considerar las repercusiones del conflicto a comienzos del siglo i d. C. con los gétulos que hemos mencionado anteriormente, que pudo afectar a la provincia del África Proconsular, haciendo que algunas tribus perdieran parte de su territorio. Así, el conflicto con esta tribu daría lugar al desarrollo de una política imperial en el territorio basada en actividades catastrales que tenían como objetivo realizar confiscaciones y establecer impuestos ${ }^{49}$. Estas operaciones fueron llevadas a cabo por el ejército y la legio III Augus$t a$, cuyos orígenes no conocemos con precisión, pero sí sabemos que fue establecida a Ammaedara (Haïdra), en el interior de la provincia de África, en el $14 \mathrm{~d}$. C., aunque pudo haber un destacamento previo en relación al conflicto con los gétulos ${ }^{50}$. Las mediciones se realizarían sobre un extenso territorio donde, además de imponerse tasas, se construiría una vía que fue finalizada al final del mandato de Augusto (14 d. C.). La construcción de esta ruta se relacionaba con el peligro existente en el suroeste con los musulamios y en el sureste con los gétulos. Por ello, se estableció un limes desde la antigua ciudad de Ammaedara (Haïdra) hasta Tacape (Gabes) ${ }^{51}$. Las consecuencias de ello tendrían gran importancia para el conflicto que tendría lugar a partir del $17 \mathrm{~d}$. C., aunque se ha discutido que sea la causa directa, como veremos en el siguiente apartado. En cualquier caso, sí está claro que las tribus de la zona vieron sus movimientos estacionales controlados o dificultados por caminos fronterizos y fortificaciones romanas, afectando a su actividad económica.

Otro factor importante en este contexto es la cuestión del vecino reino de Mauretania, vasallo de Roma. En torno al 29-27 a. C., Augusto impuso como rey a Juba II, hijo del anterior rey de Numidia Juba I, educado en Roma. Tener al frente a un rey "títere" del Imperio romano también pudo ser un factor de descontento para las tribus que estaban bajo su mando ${ }^{52}$. La importancia del reino de Mauretania con respecto a la revuelta de los musulamios fue su intervención para acabar con la guerra bajo el gobierno de Ptolomeo, aunque recientemente se ha planteado que Juba II

48. Raven, S.: Rome in Africa. London, 1969, p. 63.

49. Sobre la frontera romana en el norte de África durante el gobierno de Augusto y las primeras delimitaciones del territorio, ver la reciente obra de Gú́DON, S.: La frontière romaine de l'Africa sous le Haut-Empire. Madrid, Casa de Velázquez, 2018, pp. 43-58.

50. LE BOHEC, Y.: op. cit., p. 337.

51. Berthier, A.: op. cit., p. 100.

52. WhitTAKer, C. R.: op cit., p. 594. 

PERSPECTIVAS SOBRE LAS CAUSAS DE SU ESTALLIDO

pudo intervenir antes mediante el estudio de sus acuñaciones ${ }^{53}$. Por ello, la revuelta de Tacfarinas debe entenderse dentro del contexto de avances romanos, que supusieron la apropiación de tierra, la imposición de un sistema de impuestos y la obligación de proporcionar reclutas. Conocemos, a través de la epigrafía, que la operación fue llevada a cabo por la legio III Augusta ${ }^{54}$. Aunque no tengamos más constancia de que se produjesen conflictos con la población local, la realización de este catastro pudo dar lugar a múltiples tensiones. Esta legión, inicialmente establecida en Ammaedara, fue esencial para controlar los conflictos con la población local. Su emplazamiento era estratégico, no solo por estar en uno de los extremos de la ruta, sino también porque se situaba al norte de los montes de Tébessa, dejando el camino hacia las estepas tunecinas y el acceso a Cartago y, por el noroeste a los altiplanos de Constantina. Además, se construyó otra ruta desde Lepcis Magna hacia el interior ${ }^{55}$.

\section{Historiografía: las CAUSAS de la REVUELTA}

Tácito no especifica en su relato las causas de la guerra de Tacfarinas ${ }^{56}$, aunque algunos detalles de su narración pueden proporcionar algún dato al respecto. Según Tácito, las condiciones para la paz era un lugar para asentarse él y su ejército y tierras para el cultivo, petición realizada a Tiberio que fue considerada como una ofensa por parte de un latro, diciendo así el pasaje:

Tacfarinas, aunque repetidamente desbaratado, había rehecho sus fuerzas en las regiones interiores de África, llegando a tal grado de arrogancia que envió legados a Tiberio pidiendo un asentamiento para él y su ejército, y amenazando en caso contrario con una guerra interminable $e^{57}$

Por ello, es posible plantear que las causas de la guerra se relacionarían con la intención de Tacfarinas y el resto de tribus de integrarse en un modelo económico agrícola diferente al que tendrían. La otra mención es de menor importancia y hace referencia al motivo de la rebelión de las tribus del norte de África, que se habrían alzado contra el poder romano para preservar o restaurar su libertad: "Así, pues, Tacfarinas esparció el rumor

53. VANACKer, W.: op. cit., p. 355.

54. WhitTAKer, C. R.: op. cit., p. 593.

55. Le BOHEC, Y.: op. cit., p. 341.

56. TAC., Ann. II, 52.

57. TAC., Ann. III, 73. 
de que los romanos se veían desgarrados también por otros pueblos, que por ello se retiraban poco a poco de África, y que a los que quedaban se los podía rodear si cuantos preferían la libertad a la servidumbre se lanzaban sobre ellos, ${ }^{58}$. Sin embargo, estas explicaciones encajan con una explicación estereotipada sobre los motivos indígenas para la guerra, más que con la alusión a unos factores reales.

La falta de referencias concretas sobre las causas de la guerra ha conducido a los investigadores contemporáneos a desarrollar múltiples interpretaciones, dando como resultado una interesante historiografía a la que intentaremos aproximarnos. Debemos tener en cuenta que la historiografía sobre el África romana ha sido determinada por la ocupación europea, especialmente francesa, del norte de África desde el siglo XIX, por lo que los estudios han ido de la mano de los procesos de colonización y descolonización contemporáneos. Las explicaciones que dan los autores hasta mediados del siglo xIx están cargadas de estereotipos y modelos que dan preeminencia al actor imperial frente a la capacidad de acción de la población local. El estudio de esta historiografía ha sido recogido por Gozalbes Cravioto ${ }^{59}$, aunque en nuestro caso nos centraremos en la visión del conflicto que nos ocupa por los autores que lo han tratado.

Hasta mediados del siglo Xx, las interpretaciones de las causas de la revuelta de Tacfarinas se inspiran directamente en el testimonio de Tácito y su falta de concreción ${ }^{60}$, muchas veces siguiendo estereotipos sobre la población nómada y concibiendo a Tacfarinas como latro. Podemos destacar a M. P. Charlesworth ${ }^{61}$, quien señala que el problema se debe esencialmente a la oposición entre el tipo de vida urbana itálico y la libertad de movimiento nómada. A partir de los años 50 y hasta los 80 podemos señalar tres vías de interpretación sobre los orígenes del conflicto en las que se agrupan los distintos autores. En primer lugar, aquellos que proponen una explicación general por las consecuencias "inevitables" de la oposición de "civilizaciones", como P. Romanelli ${ }^{62}$ o G. Picard ${ }^{63}$.

El segundo grupo se centra en el control de las tierras, ya sea mediante una explicación relacionada con la demanda de tierras de los itálicos

58. TAC., Ann. IV, 24.

59. Gozalbes Cravioto, E.: "Visiones del África romana", Espacio, Tiempo y Forma, Serie II, Historia Antigua, 28, pp. 147-178.

60. CaGnat, R.: L'armée romaine d'Afrique et l'occupation militaire de l'Afrique du nord sous les empereurs. Paris, 1913, p. 9.

61. Charlesworth, M. P.: The Cambridge Ancient History, t. 10, 1934, p. 643.

62. Romanelli, P.: op. cit., p. 228.

63. Picard, G.: La civilisation de l'Afrique romaine. Paris, 1959, p. 104. 
PERSPECTIVAS SOBRE LAS CAUSAS DE SU ESTALLIDO

en África, o por la cuestión nómada. Por ejemplo, M. Rachet ${ }^{64}$ explica la guerra por la "feroz" voluntad de la población seminómada de defender las tierras de pasto, necesarias para su subsistencia y amenazadas por una ocupación cada vez mayor del territorio por los itálicos. Pero trabajos más recientes han señalado que la política de Augusto fue muy cautelosa en la provincia de África y que no se realizó ninguna deducción por parte de los colonos en los puertos de la Sirte. De hecho, la onomástica y la cerámica muestran que la colonización no comenzó verdaderamente hasta la época flavia ${ }^{65}$.

En el tercer grupo estaría el estudio de G. Alföldy ${ }^{66}$, quien considera que las causas de la revuelta de Tacfarinas se relacionan con la paralización de la política de urbanización, lo cual conllevaría la protesta de grupos nómadas que querrían asentarse. El pasaje narrado por Tácito en que Tacfarinas muestra interés en asentarse en el territorio, puesto que pide al emperador Tiberio tierras para asentarse y cultivar a cambio de poner fin a la guerra (Ann. III, 73), podría explicar esta interpretación.

A partir de los 80 se han realizado las interpretaciones más destacadas, dejando atrás muchos de los modelos explicativos anclados en los primeros estudios sobre el África romana. Una de las más interesantes la plantea J. M. Lassère en torno a la vinculación de las causas de la guerra con la apertura, bajo la dirección del procónsul L. Nonius Asprenas, de una ruta estratégica a través de las estepas del sur del África, ya controlada militarmente por Roma, pero no poblada por colonos hasta los años 2930 d. C. En 1969, S. Raven ${ }^{67}$ ya vinculaba de forma directa la construcción en el $14 \mathrm{~d}$. C. de la vía (que califica como militar porque la construyó la legio III Augusta) entre Tacape (Gabes) y Ammaedara (Haïdra), pasando por Capsa, con la revuelta, calificando la acción como una "provocación". También A. Berthier ${ }^{68}$ o M. Bénabou ${ }^{69}$ habían indicado ya antes que el contexto que dio lugar a la revuelta fue la construcción de esta vía de comunicación, que supuso la autoridad efectiva de Roma sobre parte del sur tunecino donde las tribus seminómadas tenían un modo de vida basado en el traslado estacional de la montaña a la estepa. Con la construcción de

64. Rachet, M.: Rome et les Berbères: un problème militaire d'Auguste à Dioclétien. Bruxelles, 1970, pp. 88-90.

65. Lassère, J. M.: "Un conflit "routier": observations sur les causes de la guerre de Tacfarinas", Antiquités africaines, 18, 1982, p. 12.

66. Alföldy, G.: "La politique provinciale de Tibère", Latomus, 24, 1965, p. 829.

67. Raven, S.: op. cit., p. 44.

68. BERTHIER, A.: op. cit., pp. 100-101.

69. Bénabou, M.: La résistance africaine à la romanisation. Paris, 1976, pp. 75-76. 
la vía y el control romano vieron imposibilitado este traslado y sus tierras ocupadas, lo cual les condujo a la lucha.

Este último autor ha destacado en la historiografía sobre el África romana por hacer hincapié en la oposición africana a la romanización y, en este sentido, su interpretación de la revuelta de Tacfarinas se centra en explicar las características de los musulamios y de su territorio en el Muthul (oued Mellègue) con amplias posibilidades económicas. Este autor incide en el carácter nuevo de la guerra con respecto a los anteriores alzamientos de los musulamios ${ }^{70}$. Por ello señala que su forma de organizarse otorga a la guerra una importancia particular dentro de la historia de la resistencia africana a la romanización, puesto que fue concebida como inevitable por la necesidad de recuperar las tierras.

J. M. Lassère ${ }^{71}$ explica esta interpretación por extenso en un artículo donde considera que la apertura de esta ruta es el único evento conocido que pudo haber llevado a la sedición. Esta vía tenía un rol estratégico, puesto que fue diseñada como un camino de circunvalación que permitiría a las tropas de hiberna castra de Ammaedara patrullar fácilmente desde la Dorsal tunecina hasta la Pequeña Sirte. La nueva ruta resolvió el problema planteado por lo que hoy denominamos el istmo de Gabes, una zona de paso obligado entre el mar de Lotófagos y Chott el-Djerid ${ }^{2}$. Roma debió preservar esta vía de unión en las rutas terrestres desde antiguo ${ }^{73}$, cuyo objetivo sería también consolidar el resultado de la guerra con los gétulos. El control e intervención de Roma en este espacio fronterizo que conecta rutas esenciales para comerciantes y población nómada del territorio estaría en la base del conflicto de Tacfarinas, puesto que interrumpiría la trashumancia con el valle del Muthul.

Lejos de ser un conflicto por la posesión de las tierras, la guerra parece tener, según este autor, sus orígenes en una rivalidad por el control de los ejes de movimiento y de supervivencia ${ }^{74}$. Argumenta que los musulamios, antes de la época de Tacfarinas e incluso de Yugurta, combinaban la cría de ganado con la agricultura, lo cual le ayuda a sostener que una ruta, que era solo una línea de control, podría haber inquietado a los dos pueblos que estaban aliados contra el Imperio. Esta interpretación manifiesta la

70. BÉnabou, M.: op. cit., pp. 76-78.

71. LASSÈre, J. M.: op. cit., p. 13.

72. LASSÈRE, J. M.: op. cit., p. 20.

73. Pero los miliarios encontrados en la ruta de Lepcis Magna a Tacape no son anteriores al siglo i. Un ejemplo de estos miliarios que reflejan la finalización de la vía en el 14 d. C. bajo el control del procónsul L. Asprenas es un epígrafe encontrado entre Capsa y Tacape: $A E, 1905,177$.

74. LASSÈRe, J. M.: op. cit., pp. 23-24. 
PERSPECTIVAS SOBRE LAS CAUSAS DE SU ESTALLIDO

importancia que tenía para Roma el control de las rutas que le permitiesen moverse rápidamente por el territorio africano, cuyas condiciones geográficas planteaban dificultades en muchas ocasiones. Lassère también indica que no se trata de justificar la guerra mediante una ruptura de la economía ni en el establecimiento de una nueva, pero sí en la posible adaptación a las nuevas corrientes económicas y mercados en torno a los puertos de la Pequeña Sirte y la estepa septentrional, de las que Roma sería la beneficiaria y contra la que las poblaciones locales se levantarían.

En este sentido, se ha señalado que la nueva ruta no pudo ser una barrera efectiva ante las migraciones pastorales porque las vías no deben ser concebidas como impedimentos al movimiento, sino como catalizadoras del mismo ${ }^{75}$. Por tanto, podríamos pensar que la intención no era impedir las migraciones nómadas, sino controlarlas. La cuestión sería cómo ese control pudo derivar a una rebelión de esta escala, por lo que se ha señalado que la vía de comunicación pudo tener un papel de marcador simbólico de los límites territoriales del control romano que daría lugar a dicha reacción ${ }^{76}$. Por otra parte, consideramos que no debemos concebir la construcción de la ruta entre Tacape y Ammaedara como un medio de Roma para cortar las migraciones de pastores en favor del incremento de la agricultura, puesto que esta ya era practicada en las zonas fértiles. La población norteafricana no necesitaba las instrucciones romanas para sacar provecho de ellas, puesto que se adaptaban a las condiciones del territorio ${ }^{77}$.

Por su parte, Y. Le Bohec cree que las causas se vinculan con la intervención del poder romano para controlar las poblaciones e implantar un sistema sedentario frente a poblaciones que eran seminómadas. También alude a la construcción de la ruta que hemos comentado. De hecho, otra vía en Lepcis Magna provocó consecuencias similares en la Tripolitania ${ }^{78}$. Sin embargo, considera que la causa principal del conflicto fue la instalación de la legio III Augusta en Ammaedara (Haïdra). Este lugar será el centro de un nuevo sistema defensivo llamado "sistema del suroeste tunecino" que permanecerá hasta época de los Flavios ${ }^{79}$. Por otro lado, R. $\mathrm{Kath}^{80}$, aunque sigue la hipótesis de Lassère, hace hincapié en el coste de

75. ISAAC, B.: The limits of Empire. The Roman army in the East. Oxford, 1992, p. 103.

76. Cherry, D.: Frontier and society in Roman North Africa. Oxford, 1998, p. 37.

77. Whittaker, C. R.: "Land and Labour in North Africa", Klio, 60, 1978, p. 345.

78. Le Bohec, Y.: Histoire de l'Afrique Romaine (146 J.-C.-439 après J.-C.). Paris, 2005, p. 57.

79. Le Bohec, Y.: La Troisième Légion Auguste. Paris, 1989, pp. 341-342.

80. KaTH, R.: "Die Straße als provincia: die römische Raumerfassung und der Konflikt mit den Musulamii (1. Jh. n. Chr.)", en Kath, R. y RiEger, A. K. (eds.): Raum-Landschaft. 
la construcción de la vía de comunicación, lo cual puede aportar algunos matices de interés. Ha sugerido que las comunidades indígenas cercanas a la ruta debieron pagar importantes costes tanto en trabajo como en recursos materiales. Esta sería una de las causas del conflicto. Sin embargo, las referencias de Tácito señalan que la revuelta comenzó en el 17 d. C. y, en este momento, la vía había sido terminada tres años antes ${ }^{81}$.

Por su parte, P. Trousset ${ }^{82}$ centra su hipótesis en la importancia de la caída del monopolio de comercio nómada local. Los comerciantes indígenas debieron seguir la ruta comercial tradicional, mientras que los comerciantes itálicos la habrían redirigido usando la creada por Roma, por lo que los comerciantes indígenas se convertirían fácilmente en apoyos para Tacfarinas. No tenemos información sobre este posible monopolio de los comerciantes indígenas ni tampoco de la intervención de los itálicos. Solo Tácito vincula los rebeldes con los comerciantes itálicos y la relación es positiva (Ann. IV, 13). En consecuencia, es difícil explicar las causas de la revuelta según lo expuesto por Trousset.

Otra hipótesis es la que propone B. D. Shaw ${ }^{83}$, que considera que las causas residen en el descontento de los auxiliares que habían luchado con Roma en la guerra con los gétulos, puesto que habrían esperado una recompensa, la ciudadanía romana o tierras para cultivo, sin recibirla ${ }^{84}$. Esta visión sigue en parte a R. Syme ${ }^{85}$, quien señaló que la revuelta estaba vinculada con la decepción de los auxiliares indígenas que pretendían integrarse y promocionar dentro del Imperio romano. Sin embargo, no tenemos referencias de dichos auxiliares en el ejército romano durante la guerra de los gétulos. Además, resulta difícil vincular la formación de grandes coaliciones (como la que está presente en la revuelta de Tacfarinas) con los beneficios de un pequeño grupo de auxiliares descontentos con el trato del Imperio romano.

Por su parte, W. Vanacker ${ }^{86}$ propone un argumento basado en el análisis de las evidencias literarias, epigráficas y arqueológicas, junto con

Wiesbaden, 2009, pp. 155-157.

81. VANACKER, W.: op. cit., p. 342.

82. Trousset, P.: "Le tarif de Zaraï: essai sur les circuits commerciaux dans la zone présaharienne", Antiquités africaines, 38-39, 2002-2003, p. 368.

83. Shaw, B. D.: "Fear and loathing: the nomad menace and Roman Africa", en Wells, C. M. (ed.): Roman Africa. Ottawa, 1982, pp. 41-42.

84. Podemos relacionar este deseo con el pasaje de Tácito donde alude a la petición de Tacfarinas de sedes y concessio agrorum, es decir, de tierras para cultivar y asentarse (Ann. IV, 73).

85. SYME, R.: op. cit., pp. 129-133.

86. VANACKer, W.: op. cit., pp. 352-354. 
PERSPECTIVAS SOBRE LAS CAUSAS DE SU ESTALLIDO

observaciones antropológicas sobre las migraciones de población dedicada al pastoreo en el Túnez actual. Este autor considera que el alzamiento es resultado de las actividades catastrales iniciadas tras la guerra con los gétulos, y que conllevó impuestos y confiscaciones. La actuación de la administración romana en el territorio para gestionar las tierras explica el asentamiento de la legio III Augusta en Ammaedara, puesto que se había ordenado a los soldados la realización de un extenso catastro de la tierra sobre el que se realizó la vía entre esta ciudad y Tacape, que conduciría a delimitar e imponer tasas en los territorios. La población reaccionaría, primero enviando una embajada a Roma para conseguir mejores condiciones, como se ha constatado en otros casos. Al no obtener una respuesta satisfactoria, comenzaría el conflicto con apoyo de otras tribus en la misma situación. Por último, en una reciente obra, S. Guédon ha tratado de forma excepcional la frontera romana en el norte de África durante el Alto Imperio. Esta autora se posiciona también en esta línea interpretativa, entendiendo que la intervención económica y militar romana en el territorio generó un malestar que condujo al estallido del conflicto ${ }^{87}$.Tras este repaso historiográfico podemos concluir varias ideas. Se han descartado las visiones estereotipadas del África romana que pretenden explicar la revuelta como resultado del choque entre dos modelos antagónicos (sedentario y nómada) o la incapacidad de la población local de alcanzar modelos económicos concebidos como más avanzados (sin tener en cuenta que las circunstancias del territorio pueden conducir a que el modelo que desarrollan sea el más adecuado) a partir del único estudio de las fuentes literarias, las cuales muestran una realidad desde una óptica externa y una perspectiva de alteridad. No debemos despreciar su validez histórica, pero sí someterlas a crítica y determinar qué procesos esconden. La mayoría de interpretaciones recientes sobre la guerra de Tacfarinas se han centrado en la importancia de la movilidad territorial y los modelos económicos de la población local y de Roma.

Consideramos que las causas de la guerra estarían relacionadas con la defensa de los intereses y recursos locales, alterados por la presencia romana, mientras que la intención de integrarse en el sistema económico romano sería un deseo de las élites, pues son estas las beneficiadas de la ocupación romana como intermediarias. Por otra parte, creemos que el estudio de otras fuentes (numismáticas, arqueológicas o epigráficas) ha abierto nuevas vías de comprensión del conflicto, por lo que no debemos considerar que, por su amplio recorrido historiográfico, todo está dicho acerca de la guerra de Tacfarinas. La extensión limitada de este trabajo

87. GuÉDON, S.: op. cit., pp. 67-78. 
no ha permitido profundizar en estos estudios, pero sirva de ejemplo las aportaciones epigráficas de Lassère en su artículo del año 1982 o el estudio de amplia variedad de fuentes realizado por Vanacker ${ }^{88}$, especialmente en relación a la numismática.

\section{Desarrollo del Conflicto: las campañas romanas contra Tacfarinas}

Uno de los aspectos esenciales para comprender el carácter de esta guerra y su larga duración que se ha señalado por diversos autores ${ }^{89}$ es la personalidad y circunstancias de Tacfarinas, puesto que sirvió en las tropas auxiliares del ejército romano para desertar posteriormente y acaudillar grupos desarticulados con una disciplina similar a la de Roma ${ }^{90}$. Al respecto, se ha señalado que la formación recibida y el propio desarrollo de la guerra dieron lugar a la aparición de cualidades militares en los musulamios que probablemente no tenían previamente. Tacfarinas les enseñó el arte militar y aplicó la disciplina y organización que había aprendido en el ejército romano. Esta circunstancia condujo a que, cuando Roma los sometió, no dudó en aprovechar su experiencia militar para reclutar tropas auxiliares, algo atestiguado epigráficamente con la cohors Musulamiorum $^{91}$, aunque se tendría en cuenta no situarlas en frentes locales para evitar riesgos. Lo cierto es que se ha asumido el liderazgo de Tacfarinas sin mayor cuestionamiento. Ningún autor contemporáneo se ha planteado su verdadero papel, asumiendo lo que Tácito señala al comienzo de su relato sobre su dirección de un conjunto de tribus africanas:

Este era un númida que había servido en tropas auxiliares en campamentos romanos; luego desertó y empezó por reunir a grupos nómadas habituados al robo para dedicarse al pillaje y al saqueo; más adelante los organizó en plan militar con enseñas y por escuadrones, para acabar como caudillo no de una tropa desorganizada, sino del pueblo de los musulamios... Se dividió el ejército de manera que Tacfarinas se quedara en el campamento con hombres escogidos y armados a la manera romana para habituarlos a la disciplina y a obedecer órdenes ${ }^{92}$.

88. VANACKER, W.: op. cit.

89. Rachet, M.: op. cit., pp. 84-86; BÉnABOU, M.: op. cit., pp. 77-78.

90. TÁc., Ann. II, 52, 2.

91. Lassère, J. M.: "Le recrutement romain et les Musulames", en LANCEL, S. : Histoire et archéologie de l'Afrique du nord. Actes du IV colloque international (Strasbourg, avril 1988), II. Paris, 1991, pp. 300-304.

92. TAC., Ann. II, 52. 
PERSPECTIVAS SOBRE LAS CAUSAS DE SU ESTALLIDO

Este fragmento nos permite comentar varias ideas. En primer lugar, Tacfarinas pudo actuar como intermediario con respecto al Imperio romano, pero no ser un líder efectivo de todas las tribus que intervinieron en la guerra. No tenemos fuentes emic, y dentro de las fuentes grecolatinas tan solo Tácito da cuenta de este conflicto por extenso. Como consecuencia, hemos asumido lo que dice al respecto, pero creo que es apropiado reflexionar sobre ello y plantear la posibilidad de que la figura de Tacfarinas no fuera la de un dirigente sino un intermediario con el Imperio, así como parece lógico pensar que cada tribu tuviera su propio líder. Otro aspecto importante de este fragmento es observar la organización del ejército de Tacfarinas para la guerra, combinando una parte más reglada y otra caracterizada por la guerrilla.

Por otro lado, cabe destacar la larga duración de la guerra, comparable con la conquista de la Galia, lo cual podría haber impresionado a los romanos hasta el punto de que algunos autores plantean que pudo organizarse un "partido por la paz" ${ }^{93}$. Lo cierto es que cabe dudar de este impacto puesto que, como ya hemos expuesto antes, solo Tácito ofrece un relato extenso sobre la guerra y prácticamente es la única fuente literaria. Los enfrentamientos se prolongaron durante siete años (17-24 d. C.) y se resolvieron con cuatro campañas que los generales romanos dirigieron contra las ofensivas de Tacfarinas. Para sostener tantos años de lucha, Tacfarinas debió tener acceso a un gran número de efectivos militares procedentes de diversas tribus y recursos, así como tener el control de vías de comunicación para moverse entre las provincias. En la introducción hemos comentado las dificultades para determinar el espacio sobre el que se produjo el conflicto, pero, si consideramos los pueblos que intervinieron, podemos establecer que esta tendría lugar al sur y al oeste de la provincia de África ${ }^{94}$. La vinculación con la cordillera del Aurés es clave, donde además se sitúa la legio III Augusta, puesto que es la conexión entre el valle y la cordillera. Controlar esta zona de paso de las tribus es vital para Roma. Es preciso señalar también que en la guerra no solo intervino la legión y sus auxiliares, sino también la legio IX Hispana desde el 20 al 23 d. C.

La primera campaña fue liderada por M. Furius Camilus, procónsul de la provincia de África en el 17-18 d. C., obteniendo los ornamentos triunfales debido a su actuación frente a las tropas de Tacfarinas, a las que venció $^{95}$. Posteriormente le sucedió en el cargo L. Apronius desde el año

93. Rachet, M.: op. cit., p. 105.

94. LE BOHEC, Y.: op. cit., pp. 343-344.

95. TAC., Ann. II, 52, 1. 
18 al 21. En este contexto, Tacfarinas consiguió sitiar una cohorte romana en un castra situado en los alrededores del río Pagyda, cuya ubicación se desconoce, aunque M. Rachet ${ }^{96}$ considera que estaría situado en los confines del África Proconsular y constituiría un primer esbozo de limes o una plaza fuerte en la retaguardia de la línea de defensa del territorio romano que fueron antiguos territorio de paso de los musulamios.

Después de este acontecimiento, Tacfarinas sufrió una derrota en Thala $^{97}$ situada a poca distancia de Ammaedara. Gracias a esta victoria para Roma, el procónsul obtuvo los ornamentos triunfales y su hijo, $L$. Apronius Caesianus, que hizo retroceder a los númidas hacia el desierto, fue premiado con el septemviratus epulonum ${ }^{98}$. En esta primera campaña contra Tacfarinas, Juba II ya había participado con Furius Camilus, como atestiguan las 18 monedas de Juba II con la efigie de la victoria ${ }^{99}$. Por otro lado, la legio IX Hispana acudiría desde Panonia al África Proconsular tras la derrota en Pagyda y permanecería en el territorio hasta el 23 d. C., momento en que Tiberio consideró que la situación estaba controlada, pero la guerra continuaría hasta el año siguiente, como ya hemos visto en un fragmento de los Annales en el segundo apartado de este trabajo.

El tercer encargado de la guerra contra Tacfarinas fue Iunius Blaesus, procónsul desde el 21 al 23 d. C. Fue honrado con los ornamentos triunfales como sus predecesores y además el título de imperator. Su estrategia consistió en construir una serie de castella in limine belli y en dividir sus efectivos en tres columnas ${ }^{100}$. Una estaba a cargo del legado Cornelio Escipión y cubría Leptis ${ }^{101}$ y cortaba las comunicaciones con la retaguardia hacia el país de los garamantes; la segunda, estaba dirigida por el hijo de Blaesus y defendía Cirta y los pagi Cirtensium. Por último, Iunius Blaesus dirigió la élite de las tropas y estableció una serie de fortines en lugares estratégicos, cercando a Tacfarinas ${ }^{102}$.

El objetivo podría ser desactivar la acción conjunta de los cinitios, que estaban encargados de cortar las comunicaciones romanas con Leptis, musulamios y garamantes. La amplitud de esta batalla ha sido cuestionada por

96. RACHET, M.: op. cit., p. 98.

97. TÁc., Ann. III, 21, 2-4.

98. LE BOHEC, Y.: op. cit., p. 345.

99. Mazard, J.: Corpus Nummorum Numidiae Mauretaniaeque. Paris, Arts et Métiers Graphiques de l'Algérie, 1955, p. 89 y p. 104.

100. TAC., Ann. III, 74, 1-2.

101. Tácito no especifica de qué Leptis se trata. BERTHIER (1981, p. 105) considera, sin dudas, que es Leptis Minor; pero Le BoHec (1989, p. 345) señala Lepcis Magna sin aportar una explicación.

102. LE BOHEC, Y.: op. cit., p. 345. 
PERSPECTIVAS SOBRE LAS CAUSAS DE SU ESTALLIDO

Berthier ${ }^{103}$ en relación a la atribución de Cirta, normalmente identificada con Constantina, pero que este autor vincula con Le Kef. Argumenta que los romanos no tenían tantos efectivos como para controlar un frente tan amplio, de Cirta a la Pequeña Sirte, mientras que la distancia entre Cirta y Le Kef es más razonable.

El siguiente episodio que narra Tácito ${ }^{104}$ sucede siendo procónsul $P$. Cornelius Dolabella (23-24 d. C.). Este fue consciente de la dificultad que suponía ganar la guerra contra un enemigo caracterizado por sus movimientos rápidos en el territorio que practicaba la guerrilla y dirigía un ejército pesado organizado siguiendo los esquemas del ejército romano. Tiberio había ordenado el abandono de la legio IX Hispana en el 23 d. C. porque pensaba que la guerra ya estaba controlada, pero fue necesaria la ayuda del rey Ptolomeo de Mauretania, además de continuar la táctica de Blaesus de dispersión de las tropas romanas. En este sentido, siempre se ha asumido que la ayuda de este reino vasallo de Roma había sucedido al final de la guerra, en el año 24 d. C. con el sucesor de Juba II, Ptolomeo. Sin embargo, recientes estudios parecen aludir a una colaboración durante todo el conflicto, como hemos visto en la campaña del 17-18. El impacto de la inestabilidad política causada por el estallido del conflicto debió ser destacado en Mauretania. Las evidencias numismáticas son el elemento que ha permitido señalar que los reyes clientes de Mauritania, Juba II y Ptolomeo, apoyaron a Roma durante todo el desarrollo de la guerra y no solo, como se ha deducido historiográficamente a partir del relato de Tácito, al final del conflicto junto al procónsul Dolabella ${ }^{105}$. Estas acuñaciones portan la efigie de la Victoria y cronológicamente se sitúan en el reinado de Juba II, sin que podamos relacionarlas con otro acontecimiento bélico en el reino ${ }^{106}$.

Siguiendo con lo sucedido estando al mando Dolabela, el procónsul dividió su ejército en cuatro columnas. Los pequeños destacamentos encargados de hacer incursiones rápidas fueron dirigidos por oficiales mauros especialistas en la práctica de la guerrilla ${ }^{107}$. Durante este tiempo, Tacfarinas sitió Thubuscum ${ }^{108}$, pero no obtuvo éxito y terminó huyendo hasta

103. Berthier, A.: op. cit., p. 105.

104. TAC., Ann. IV, 25.

105. VANACKer, W.: op. cit., p. 355.

106. BÉnabou, M.: op. cit., p. 79.

107. TÁc. Ann. IV, 24.

108. Syme (1951) lo identificó con Thubursicu Numidarum (Khamissa) y así lo acepta Berthier (1981, p. 105). 
Auzea $^{109}$, donde se suicidó ${ }^{110}$. Dolabella no fue recompensado con los ornamentos triunfales, mientras que a Ptolomeo se le transmitió el bastón de marfil, la toga bordada y se le saludó con el título de rey aliado y amigo del pueblo romano ${ }^{111}$. Sobre esta cuestión y la intervención o el papel de Tiberio al respecto ya hemos comentado algunas de las principales interpretaciones en el segundo apartado.

\section{CONSECUENCIAS DE LA GUERRA}

La victoria romana frente a Tacfarinas tuvo diversas consecuencias para la población del territorio y su administración, pero también para la política imperial con respecto a África. De este modo, el resultado fue diferente para los distintos grupos locales que participaron ${ }^{112}$. Las tribus sublevadas no recuperaron el territorio perdido por la intervención de Roma ${ }^{113}$. Los garamantes no volvieron a actuar hasta casi medio siglo después, cuando amenazaron las ciudades de la Tripolitania. Por su parte, los mauros aprovecharon el asesinato de Ptolomeo por Calígula para alzarse, mientras que los musulamios y los cinitios desaparecen de las fuentes durante más tiempo, aunque se integraron en el Imperio. Tiberio permitió a los musulamios instalarse en una fracción del territorio romano, al oeste de la Proconsular, en la región de Madaura, entre Sbeïtla y Haïdra ${ }^{114}$. Por tanto, estaban cerca de la ruta estratégica construida por Roma, asegurando asî su control. La presencia, dentro del territorio romano, de población de origen latino y de una importante tribu se entiende por la cercanía de la legio III Augusta, establecida en Ammaedara, conectada con Cartago.

En cuanto a Roma, después del fin del conflicto extendió su zona de dominio, como muestra la realización del catastro de una vasta zona del sur de la actual Túnez, que sería llevado a cabo por la legio III Augusta bajo el mando del procónsul C. Vibius Marsus ${ }^{115}$. Parece que tendría lugar entre el 29 y el 30 d. C. y, dado que esta región estuvo inmersa en la guerra contra Tacfarinas, los investigadores consideran que ambos hechos están

109. Se había mantenido que se trataba de Auzia (Aumale) pero Berthier (1981, p. 106) defiende que es Aubuzza (Henchir Jezza). Rachet (1970, p. 120) tampoco considera que se Aumale, pero no precisa otra ciudad.

110. TÁc. Ann. IV, 25.

111. TÁc. Ann. IV, 26.

112. Le BOHEC, Y.: op. cit., pp. 345-346.

113. Bénabou, M.: op. cit., p. 82.

114. RACHET, M.: op. cit., p. 125.

115. Bénabou, M.: op. cit., p. 83. 

PERSPECTIVAS SOBRE LAS CAUSAS DE SU ESTALLIDO

conectados. Asimismo, se ha señalado una relación entre el catastro y la construcción de la vía entre Ammaedara y Tacape, finalizada en el 14 d. C. Según M. Bénabou ${ }^{116}$ esta vía no podía desempeñar al mismo tiempo el papel de línea fronteriza y el de cordón umbilical de la legión, por lo que fue necesario asegurar el control de las tierras situadas al sur de dicha vía, razón por la que hay algunas evidencias de líneas de demarcación, realizadas por la legio III Augusta en tiempos del procónsul C. Vibius Marsus, en el norte de Chott el-Fedjedj, por ejemplo en emplazamientos como Aquae Tacapitanae (Al-Hammah / El-Hamma) ${ }^{117}$. Por su parte, Le Bohec ha propuesto que en el $14 \mathrm{~d}$. C. se construiría esta ruta estratégica que asegurara el control del territorio para su catastro; pero la guerra, iniciada en el 17 hasta el 24 d. C., atrasó la operación, que culminaría en el 29-30 d. C.

Existen divergencias en torno a la extensión de este catastro y su finalidad. Mientras que algunos autores señalan que afectaría a la zona de los chotts, otros indican que sería en torno a Haïdra e incluso hasta Ghadamés, una ciudad muy al sur de la actual Túnez. En cuanto a la finalidad, se ha rechazado que fuese puramente económica, porque no hubo una inmigración masiva de población tras el catastro, aunque Rachet ${ }^{118}$ sí considera que se produjo una importante llegada de itálicos. Tampoco parece que tenga una finalidad puramente fiscal por el hecho de haberse producido después de una gran revuelta.

Berthier ${ }^{119}$ considera que la anexión de la zona al sur de la vía Tacape-Ammaedara tras el catastro se vincula con un interés económico, pero sobre todo estratégico, con el objetivo de crear una zona de seguridad. En este sentido, desde el punto de vista militar, la guerra tuvo como consecuencia precisamente un cambio de organización estratégica mediante la creación del sistema defensivo de Constantina. Por ello, Le Bohec ${ }^{120}$ considera que se trata de una operación "más militar que política, y más política que fiscal", puesto que el Estado romano tomó posesión, mediante la acción de la legio III Augusta, de un territorio que pertenecía a los $N y b$ genii, como se ha atestiguado epigráficamente.

Por otro lado, las consecuencias de la guerra deben comprenderse también como un cambio de actitud por parte de Roma que determinó la política imperial en África durante los años siguientes, tal y como hemos

116. BÉnABOu, M.: op. cit., pp. 84-85.

117. CIL VIII, 22786a: [Leg(io) III A]ug(ustae) / [leimitav]it / [C(aio) Vibio] Mars[o] / [proc]o(n)s(uli) III / d(extra) d(ecumani) LV/ [u(ltra)] k(ardinem) CCC.

118. RACHET, M.: op. cit., pp. 57-58.

119. Berthier, A.: op. cit., p. 121.

120. Le BoHec, Y.: op. cit., pp. 347-348. 
visto con el catastro realizado en la zona en el 29-30. Más allá de la naturaleza de sus objetivos, está claro que fue un modo de controlar un territorio que había supuesto grandes dificultades para el Estado romano, pero también que este asumió la importancia de la movilidad en el territorio.

Con la ampliación del territorio del África Proconsular al sur tras la guerra, cambió la situación del procónsul que estaba al mando de esta provincia senatorial. Disponiendo de una provincia económicamente importante y de un ejército experimentado, era susceptible de provocar problemas al Imperio. Calígula fue el primero en reaccionar en este sentido, tal y como señala Tácito: “Más tarde, Gayo César (Calígula), de carácter retorcido y temeroso de Marco Silano, que controlaba África, quitó la legión al procónsul para entregarla a un comandante militar enviado a tal efecto" ${ }^{121}$. Por tanto, Calígula estableció un legado que acompañaría al procónsul que recibió el mando de la legio III Augusta y de los auxiliares del ejército africano, mientras que el procónsul de Cartago quedó con un papel meramente administrativo. Por tanto, mientras que Tiberio impulsó una política de control no agresivo tras el final de la guerra de Tacfarinas, a partir de la llegada al poder de Calígula se inició una política de conquista más agresiva que condujo incluso a acabar con el rey Ptolomeo de Mauretania $\mathrm{y}$ transformar el reino en provincia romana.

\section{CONClusiones}

En primer lugar, cabe destacar que la reconstrucción e interpretación del conflicto, frente a la historiografía tradicional, hace hincapié actualmente en la naturaleza dinámica de las relaciones entre la población local y la administración romana en el norte de África. Dichas relaciones han sido descritas durante muchas décadas como estáticas y unilaterales o en términos de antagonismo económico. La revuelta fue comprendida primero como el choque entre dos modos de vida incompatibles (pastoreo nómada o agricultura sedentaria), y más tarde como un acto de bandidaje que interrumpía la cohesión entre ambas civilizaciones. Ahora apostamos por una visión en que la revuelta sea entendida como un acto de negociación negativa que ilustra cómo un acto de insurgencia pudo haber tenido un impacto efectivo en la administración romana. El estallido de la guerra, sus causas y consecuencias, muestran la importancia no solo de apreciar la complejidad y el carácter discrepante de las trayectorias de integración de tribus locales específicas, sino también del necesario reconocimiento de la

121. TÁc., Hist. IV, 48. 
naturaleza fluida y potencialmente negociable de la política provincial de Roma en una región concreta.

Por otro lado, consideramos haber podido comprobar que los factores que fueron esenciales para el estallido de la guerra se vinculan con la necesidad de moverse en el territorio y acceder a los recursos económicos, dentro de una geografía compleja que requiere la adaptación del modelo económico al territorio en mayor medida que en otros espacios. En este sentido, creemos que la obra de M. Bénabou ${ }^{122}$ ha sido esencial en el cambio de paradigma de la historiografía francesa dominante en los estudios del África romana por el protagonismo otorgado a la población local. Igualmente, los estudios realizados sobre la legio III Augusta por Y. Le Bohec, que abarcan innumerables fuentes de estudio, han proporcionado una información fundamental para entender el proceso de provincialización y administración del territorio, cuyas operaciones catastrales y viarias eran llevadas a cabo por el ejército romano. Precisamente el papel de este en África es fundamental para comprender la organización de un territorio, pero también los conflictos que surgen con la población local, como hemos comprobado en este caso.

Otra de las ideas que podemos extraer como conclusión de este trabajo gira en torno a la cuestión de las identidades y la etnicidad ${ }^{123}$. La cuestión sería cuál es la identidad de un personaje como Tacfarinas, que ha luchado en el ejército romano, pero después "cambia de bando" y se rebela contra el Imperio para dirigir una guerra contra este. Su origen étnico es númida, pero su participación en el ejército romano supone un cambio identitario, sobre todo porque después aplicará una organización similar a la romana a sus tropas. En este sentido, cabe destacar que se ha prestado poca atención a la comprensión de la etnicidad en África en términos de contingencia histórica e identidad basada en el contexto. D. Whittaker ${ }^{124}$ considera que la esencia de la etnicidad es el cambio y la mutabilidad, sobre todo en periodos de tensión.

Uno de los problemas fundamentales que existen a la hora de definir identidades son las fuentes de las que disponemos para su estudio. Si

122. BÉnabou, M.: op. cit.

123. No es este el espacio para ello, pues solo la reflexión sobre este concepto daría lugar a un gran debate. Aquí nos referimos a la etnicidad siguiendo la definición de D. Whittaker que la concibe en el marco del África romana en términos de contingencia histórica e identidad basada en un contexto. Véase WhitTaker, D.: "Ethnic discourses on the frontiers of Roman Africa", en Derks, T. y Roymans, N. (eds.): Ethnic Constructs in Antiquity: The Role of Power and Tradition. Amsterdam, Amsterdam University Press, 2009, pp. $90-92$.

124. WhitTAKer, D.: op. cit., p. 191. 
pretendemos "clasificar" étnicamente a un personaje como Tacfarinas, pero no tenemos fuentes propias y nos basamos en el relato etic de Tácito, que además está condicionado por toda una serie de intereses, podemos caer en las definiciones estereotipadas. Tacfarinas es concebido como latro o bandido, destacando su deserción del ejército romano y su único interés en practicar el bandidaje. No todos los líderes de guerras de gentes locales son definidos como latrones, sino que algunos son ensalzados por sus valores o respetados por su mayor grado de romanización. Parece que el estereotipo sobre el África romana, donde las tribus son concebidas como lejanas al nivel superior que ocupa Roma (y que nunca logran alcanzar) es una construcción historiográfica que procede de unas fuentes antiguas cargadas de este tipo de prejuicios y de una alteridad negativa.

Otro ejemplo de la etnicidad cambiante es el caso de los musulamios, que constituían una confederación de tribus que primero fueron reclutados como soldados étnicos (Tacfarinas uno de sus líderes) mientras Roma penetraba hacia el sur en el I d. C. Después son localizados epigráficamente en el II d. C. en Túnez-Argelia como parte de un movimiento nómada desde los oasis del sur que Trajano y Adriano quisieron controlar. Por ello, D. Whittaker destaca la importancia de contextualizar la etnicidad, que es múltiple y cambia según el momento.

Consideramos que se produce una mezcla con respecto a la etnicidad entre el deseo de seguridad y control del Imperio y los intereses de las poblaciones locales, especialmente la élite del territorio, que podrían aprovechar para establecer una nueva base de autoridad. Esto se comprueba en África, se ve por la creación de administración de élites gerentes y la influencia militar de las fronteras y soldados étnicos. Parece que había un procedimiento estándar para la tasación y reclutamiento en todas las provincias de la frontera. Como hemos señalado, el Imperio romano reclutó a gentes de la Proconsular que habían participado en la guerra de Tacfarinas porque hay un intento de preservar la unidad étnica, pero también de aprovechar su potencial. Estas unidades auxiliares son enviadas a luchar fuera de su territorio, como el caso de Tacfarinas, que luchó en la frontera del Rhin.

Otra cuestión sobre la que reflexionar es el papel de las vías de comunicación y las fronteras. Ambos elementos son fundamentales en la estructuración, administración y control de un territorio. El Imperio romano fue consciente de ello y la guerra de Tacfarinas también es un buen ejemplo. La construcción de la vía de Ammaedara a Tacape fue un elemento determinante para el estallido del conflicto por el control del territorio y los movimientos de la población local, pero probablemente también porque su realización (por parte de unidades militares) traería consigo importantes 
PERSPECTIVAS SOBRE LAS CAUSAS DE SU ESTALLIDO

costes económicos y humanos para la población local. Aunque no considero que se deban concebir las vías de comunicación como un freno a los movimientos, sí es cierto que esta ruta pudo alterar la libertad de la población seminómada local en sus traslados estacionales. Posiblemente no impediría que tuvieran lugar, pero el Imperio sí mantendría una supervisión y la legión podría actuar rápidamente desde su emplazamiento en Ammaedara.

Finalmente, cabría señalar que la interpretación de la guerra de Tacfarinas ha variado mucho desde comienzos del siglo xx hasta los años 70 de este, pero, por el contrario, en las últimas décadas se han realizado pocas aportaciones novedosas. No creemos que sea un tema cerrado, sino que es necesario seguir en la línea de algunos de los trabajos que hemos señalado, es decir, apostar por ir más allá del relato de Tácito y analizar otras fuentes para avanzar hacia nuevas propuestas. La propia revisión historiográfica del conflicto en este trabajo nos ha acercado hacia una visión amplia del modo en que se han tratado muchos de los conflictos en los que se plantea la dualidad entre Roma y una población local.

\section{BiBLIOGRAFÍA}

AlFÖLDy, G.: «La politique provinciale de Tibère», Latomus, 24, 1965, pp. 824-844.

Aubrion, É.: Rhétorique et histoire chez Tacite. Metz, Université de Metz, Centre de recherche Littérature et spiritualité, 1985.

BÉNABOU, M.: La résistance africaine à la romanisation. Paris, F. Maspero, 1976.

BÉNabou, M.: "Tacfarinas", Les Africains, t. 8. Paris, 1977, pp. 293-313.

Berthier, A.: La Numidie: Rome et le Maghreb. Paris, Picard, 1981.

CAGNAT, R.: L'armée romaine d'Afrique et l'occupation militaire de l'Afrique du nord sous les empereurs. Paris, 1913.

CAmps, G.: "Aux origines de la berberie: Massinissa ou les débuts de l'histoire", Libyca, 8, 1960, pp. 1-320.

Charlesworth, M. P.: The Cambridge Ancient History, t. 10, 1934.

CHERRY, D.: Frontier and society in Roman North Africa. Oxford, Clarendon Press, 1998.

Cotelloni-Trannoy, M.: Le royaume de Maurétanie sous Juba II et Ptolémée (25 av.J. C.-40 ap.J. C.). Paris, CNRS, 2002.

Decret, F.; Fantar, M. H. y Leroux, A.: L'Afrique du Nord dans l'antiquité: bistoire et civilisation, des origines au Ve siècle. Paris, Payot, 1981.

DesAnges, J.: Catalogue des tribus africaines de l'antiquité classique a l'ouest du Nil. Université de Dakar, Publications de la section d'Histoire, 1962. 
Desanges, J.: "Les territoires Gétules de Juba II", Revue des Études Anciennes, 66, 1964, pp. 33-47.

Devillers, O.: "Le Rôle des passages relatifs à Tacfarinas dans les Annales de Tacite", L'Africa Romana. Atti del VIII convegno di studio, Sassari, 14-16 diciembre 1990, 1. Sassari, 1991, pp. 203-211.

Falomir Pastor, C.: Juba II: rey de los Mauros y los Libios. Tesis Doctoral, Universidad de Valencia, 2013.

Fentress, E. W. B.: Numidia and the Roman Army: social, military and economic aspects of the frontier zone. Oxford, BAR, 1979.

Fentress, E. W. B.: “Romanizing the Berbers", Past and Present, 190, 2006, pp. 3-34.Fishwick. D. y SHaW. B. D.: "Ptolemy of Mauretania and the Conspiracy of Gaetulicus", Historia: Zeitschrift fur Alte Geschichte, 25 (4), 1976, pp. 491-494.

Gozalbes Cravioto, E.: "Visiones del África romana", Espacio, Tiempo y Forma, Serie II, Historia Antigua, 28, pp. 147-178.

GonzALÈs, A.: "La révolte comme acte de brigandaje: Tacite et la révolte de Tacfarinas", en Khanoussi, M.; Ruggeri, P. y Vismara, C. (eds.): L'Africa romana. Atti del XII convegno di studio, Olbia, 12-15 diciembre 1996, 2. Sassari, 1998, pp. 937-958.

GrÜNEWALD, T.: Bandits in the Roman Empire: myth and reality. London, Routledge, 2004.

GuÉDON, S.: La frontière romaine de l'Africa sous le Haut-Empire. Madrid, Casa de Velázquez, 2018.IsaAc, B.: The limits of Empire. The Roman army in the East. Oxford, Oxford University Press, 1992.

Kaтн, R.: "Die Straße als provincia: die römische Raumerfassung und der Konflikt mit den Musulamii (1. Jh. n. Chr.)", en Kath, R. y Rieger, A. K. (eds.): Raum-Landschaft. Wiesbaden, 2009.

LASSÈRE, J. M.: "Un conflit "routier”: observations sur les causes de la guerre de Tacfarinas", Antiquités africaines, 18, 1982, pp. 11-26.

LASSÈRE, J. M.: "Le recrutement romain et les Musulames", en LANCEL, S. : Histoire et archéologie de l'Afrique du nord. Actes du IVe colloque international (Strasbourg, avril 1988), II. Paris, 1991, pp. 229-311.

Le BoHec, Y.: La Troisième Légion Auguste. Paris, CNRS, 1989.

Le Bohec, Y.: Histoire de l'Afrique Romaine (146 J.-C.-439 après J.-C.). Paris, Picard, 2005.

Magnaro, G.: "Tacfarinas e la Sicilia (ovvero L. Apronius e il santuario ericino)", en Mastino, A. (ed.), L'Africa romana. Atti del IV convegno di studio, Sassari, 12-14 dicembre 1986. Sassari, 1987, pp. 581-585.

MazArD, J.: Corpus Nummorum Numidiae Mauretaniaeque. Paris, Arts et Métiers Graphiques de l'Algérie, 1955.

PICARD, G.: La civilisation de l'Afrique romaine. Paris, 1959. 

PERSPECTIVAS SOBRE LAS CAUSAS DE SU ESTALLIDO

RaCHET, M.: Rome et les Berbères: un problème militaire d'Auguste à Dioclétien. Bruxelles, Collection Latomus, vol. 1120, 1970.

Raven, S.: Rome in Africa. London, Routledge, 1969.

Romanelli, P.: Storia delle province romane dell'Africa. Roma, L'erma di Bretschneider, 1959.

SHAw, B. D.: "Fear and loathing: the nomad menace and Roman Africa", en

Wells, C. M. (ed.): Roman Africa. Ottawa, The University of Ottawa Press, 1982, pp. 29-50.

Sirago, V. A.: “Tacfarinas”, en Mastino, A. (ed.): L’Africa Romana. Atti del V Convegno di studio, Sassari, 11-13 dicembre 1987. Sassari, 1988, pp. 199-204.

Syme, R.: "Tacfarinas, the Musulamii and Thubursicu", en ColEman-NorTON, P. R., Bourne, F. C. y Fine, J. V. A. (eds.): Studies in Roman economic and social history in honor of Allan Chester Johnson. Princeton, Princeton University Press, 1951, pp. 113-130.

TÁcito, Annales. Introducción, traducción y notas de J. L. Moralejo. Madrid, Gredos, 1979.

TÁcito, Historias. Introducción, traducción y notas de A. Ramírez de Verger. Madrid, Gredos, 2013.

Trousset, P.: "Le tarif de Zaraï: essai sur les circuits commerciaux dans la zone présaharienne", Antiquités africaines, 38-39, 2002-2003, pp. 355373.

VANACKER. W.: "Conflicts and Instability in Mauretania and Gaius' Realpolitik", Latomus: Revue D'Etudes Latines, 72 (3), 2013, pp. 725 741.

VANACKER, W.: "Adhuc Tacfarinas: Causes of the Tiberian war in North Africa (ca. 15-24 d. C.) and the impact of the conflict on Roman imperial policy", Historia: zeitschrift für alte geschichte: revued'bistoire ancienne, vol. 64, n. ${ }^{\circ}$ 3, 2015, pp. 336-356.

WhitTaker, C. R.: "Land and Labour in North Africa", Klio, 60, 1978, pp. 331-362.

WhitTaker, C. R.: "Roman Africa: Augustus to Vespasian", en Bowman, A. K., Champlin, E. y Lintott, A. (eds.): The Cambridge Ancient History 10 (The Augustan Empire, 43 BC-AD 69). Cambridge, Cambridge University Press, 1996.

WhitTAKer, D.: "Ethnic discourses on the frontiers of Roman Africa", en Derks, T. y Roymans, N. (eds.): Ethnic Constructs in Antiquity: The Role of Power and Tradition, Amsterdam, Amsterdam University Press, 2009. 
